\title{
O recanto de um jardim - Henri Salvador em português
}

\author{
Bïa Krieger e Álvaro Faleiros*
}

\section{Chambre avec vue: "Jardin d'hiver"}

Em 2000, Henri Salvador lançou pelo selo Virgin Records um trabalho que faria história na chanson française: Chambre avec vue é uma obra em que o cantor - já com 83 anos de idade e mais de 60 de carreira - se reinventa, para muitos, de modo inesperado.

O ressurgimento de Henri Salvador, que se encontrava em certo ostracismo, se deveu, em grande medida ao trabalho e sensibilidade de um jovem produtor, Marc di Domenico. Este lhe propõe uma canção, "Jardin d'hiver". A letra e a música são da, à época estreante, Keren-Ann Zeidel, e de um compositor que se tornaria uma das figuras de relevo na paisagem cultural francesa, o produtor musical, ator e cantor Benjamin Biolay. Redescoberto por essa nova geração de admiradores que se dedicam a compor e produzir um mundo sob medida para seu reconhecido talento de intérprete, Henri Salvador reúne, em Chambre avec vue, treze canções que, muito provavelmente, não passariam de canções para um lado B de um de seus discos quinze anos antes. E abrindo o álbum está, precisamente, "Jardin d'hiver".

O sucesso imediato do trabalho projetou-o internacionalmente, fazendo dele figura omnipresente em rádio, televisão, publicações culturais e na programação de tudo que a França tem em termo de festivais, casas de

* Université du Québec à Montréal (UQàM) e Universidade de São Paulo (USP). 
show e comemorações oficiais. Esse sucesso traduziu-se em prêmios de crítica e público, culminando com um disco de diamante graças à venda de mais de um milhão de cópias.

O sucesso de Chambre avec vue não se restringiu à França, o que deu origem à ideia de se regravar o disco todo com versões internacionais. À época, por meio de seu percussionista, o brasileiro Silvano Michelino, Henri Salvador chegou a Bia Krieger que, por já trabalhar com adaptação e recriação de canções, tendo assinado e gravado diversas versões de Chico Buarque, foi convidada a reescrever a canção em português. Para podermos pensar as implicações envolvidas nesse processo de reinvenção da canção "Jardim d'hiver" em português, é necessário, antes de nos debruçarmos sobre a canção propriamente dita, esclarecer nosso entendimento das especificidades em jogo nesse tipo de recriação.

\section{A canção em tradução}

Ainda que no Brasil, pelo menos desde Augusto de Campos (1969, p.309) haja certa consciência de que "a palavra cantada/ não é a palavra falada/ nem a palavra escrita/ [...] a palavra-canto/ é outra coisa", persiste por vezes certa compreensão de que o funcionamento da canção se assemelha ao do poema. Mesmo que seja possível reconhecer na canção um série de índices textuais também pertencente ao gênero poema, ambos não se confundem pelo simples fato de que, na canção, a voz, o corpo, o arranjo, em grande medida sobredeterminam outras normatividades, como métrica, rima ou acentuação silábica. Assim, como afirmam Flores \& Gonçalves (2017, p.74), é importante evitarmos "os discursos que cobram da poética da canção regras da poética escrita", pois, como nos lembra Tatit (1997, p.117), "produzir canções significa produzir compatibilidades entre letras e melodias - às quais se agregam recursos musicais de toda ordem -, de modo a configurar um sentido coeso".

Essa primeira ressalva é um bom ponto de partida para tentarmos compreender a especificidade da arte da tradução da canção. Ainda que sejam poucas as tentativas de teorização a respeito, uma das mais retomadas é aquela proposta por Peter Low, justamente por ele problematizar a 
especificidade que a canção implica, pelo fato de ser necessariamente a combinação de dois sistemas. Segundo Low (2005, p.187):

\footnotetext{
Music can be viewed as an auditory code of communication, and specific pieces of music can be viewed as messages. Music is indeed a complex system sounds, with dimensions of pitch and harmony, duration and rhythmic patterns, dynamics and timbre. Therefore songs, being a combination of words and music, partake Jakobson has called "two particularly elaborate systems of purely auditory and temporal signs" (1971, p.701). Its follows the task of translating them should be viewed not as a narrowly linguistic operation.
}

Essa complexa equação que se produz entre a dimensão musical e a dimensão textual, levou o crítico a propor que se pense a tradução de canções a partir do "princípio do pentatlo" (penthatlon principle), baseado em cinco critérios: cantabilidade (singability), sentido (sense), naturalidade (naturalness), ritmo (rythm) e rima (rhyme). Antes de retomarmos esses critérios e saber em que medida eles ajudam a pensar a tradução aqui em jogo, é fundamental destacar, com Low, que a acessibilidade da canção traduzida para o público-alvo da língua-cultura de chegada é uma questão central, isto é, os tradutores precisam, no momento de traduzir, considerar "aspectos literários e socioculturais daquilo que Even-Zohar (...) chamou de transferência inter-sistêmica" (LOW, 2003, p.92). Cantabilidade, sentido, naturalidade e até ritmo e rima parecem estar, pois, sobrederminados pelo modo como quem traduz pensa o tipo de relação que se quer estabelecer entre a cultura de partida e a cultura de chegada. Nesse sentido, nos parece imprescindível saber o que a canção "Jardim d'hiver" nos dá a ver.

\section{"Jardin d'hiver": contextos em texto}

Para compreender o que está em jogo na canção "Jardin d'hiver" é preciso identificar o conjunto importante de referências socioculturais ali implicadas. Para tal, parece-nos necessário retomar o texto em francês, estrofe a estrofe, acompanhada de tradução semântica para que o leitor não familiarizado com tais referências ou que desconhece o francês possa acompanhar nosso raciocínio. Um primeiro cotejamento se faz, pois, necessário. 


\begin{tabular}{|c|c|}
\hline Jardin d'hiver & Jardim de inverno \\
\hline Je voudrais du soleil vert & Eu queria um sol verde \\
\hline Des dentelles et des théières & Rendas e chaleiras \\
\hline Des photos de bord de mer & Fotos à beira do mar \\
\hline Dans mon jardin d'hiver & Em meu jardim de inverno \\
\hline Je voudrais de la lumière & Eu queria luz \\
\hline Comme en Nouvelle Angleterre & Como na Nova Inglaterra \\
\hline Je veux changer d'atmosphère & Quero mudar de atmosfera \\
\hline Dans mon jardin d'hiver & Em meu jardim de inverno \\
\hline Ta robe à fleur & Teu vestido florido \\
\hline Sous la pluie de novembre & Sob a chuva de novembro \\
\hline Tes mains qui courent & Tuas mãos que correm \\
\hline Je n'en peux plus de l'attendre & Não aguento mais de tanto esperar \\
\hline Les années passent & Os anos passam \\
\hline Qu'il est loin l'âge tendre & Como está longe a tenra idade \\
\hline Nul ne peut nous entendre & Ninguém pode nos escutar \\
\hline Je voudrais du Fred Astaire & Eu queria Fred Astaire \\
\hline Revoir un Latécoère & Rever um Latécoère \\
\hline Je voudrais toujours te plaire & Queria sempre te agradar \\
\hline Dans mon jardin d'hiver & Em meu jardim de inverno \\
\hline Je veux déjeuner par terre & Eu quero um almoço no chão \\
\hline Comme au long des golfes clairs & Como ao longo dos golfos claros \\
\hline T'embrasser les yeux ouverts & Te beijar de olhos abertos \\
\hline Dans mon jardin d'hiver & Em meu jardim de inverno \\
\hline Je veux déjeuner par terre & Eu quero um almoço no chão \\
\hline Comme au long des golfes clairs & Como ao longo dos golfos claros \\
\hline T'embrasser les yeux ouverts & Te beijar de olhos abertos \\
\hline Dans mon jardin d'hiver & Em meu jardim de inverno \\
\hline
\end{tabular}

Na primeira estrofe da canção deparamos, já incialmente, como a inusitada imagem "je voudrais du soleil vert" [eu queria um sol verde]. 
Ainda que seja possível interpretá-la numa chave surrealista - basta nos lembrarmos da famosa frase de Paul Éluard "la terre est bleue comme une orange" [a terra é azul como uma laranja] —, o mais provável é a ideia de que o sol verde remeta a uma paisagem tropical onde a luz do sol costuma incidir sobre as folhagens. Além disso, o próprio jardim de inverno costuma ser um lugar em que há grande incidência de luz sobre plantas. A essa imagem somam-se outras que vão se justapondo para compor um ambiente - provavelmente a sala deste inusitado jardim de inverno onde, além das plantas, coabitam memórias e objetos de algum modo aprazíveis, com ares de boas lembranças; o que explicaria haver num mesmo ambiente "rendas e chaleiras" convivendo com "Fotos à beira do mar".

Na segunda estrofe, reforça-se a centralidade que a claridade tem na construção desse ambiente caloroso e acolhedor: "Je voudrais de la lumière/ Comme en Nouvelle Angleterre" [Eu queria luz/ Como na Nova Inglaterra]. Ainda que a Nova Inglaterra não represente um lugar especialmente luminoso para um ouvinte acostumado com a luminosidade dos trópicos, não é difícil imaginar que, para um europeu, a Nova Inglaterra represente, com efeito, uma mudança de atmosfera.

A estrofe seguinte difere consideravelmente das anteriores. Ao se ouvir a canção não é difícil compreender essa mudança, pois se trata de uma "parte B". Nela aparece um "tu" a quem o "eu" do texto se dirige. A projeção aqui não parece ser mais a do desejo rumo ao jardim imaginado e sim rumo a alguma lembrança de um passado florido, figurado pela roupa da amada - "Ta robe à fleur" [Teu vestido florido]. A alegria contida nesta imagem contrasta com o tom mais melancólico do resto da estrofe onde, "Sous la pluie de novembre" [Sob a chuva de novembro], as mãos da amada escorrem - "Tes mains qui courent" [Tuas mãos que correm] - numa espécie de espera insuportável - "Je n'en peux plus de l'attendre" [Não aguento mais de tanto esperar]. O clima nostálgico é reforçado por uma remissão aos tempos idos dos últimos versos da estrofe, onde se lê: "Les années passent/ Qu'il est loin l'âge tendre/ Nul ne peut nous entendre" [Os anos passam/ Como está longe a tenra idade/ Ninguém pode nos escutar]. Este clima é certamente reforçado pelo fato de quem canta ser um homem sabidamente idoso que, do alto de seus mais de oitenta anos, assim como a 
onda do mar que se recolhe antes de relançar-se sobre as margens, volta no tempo para melhor dar a ver o seu jardim imaginado.

Assim, na penúltima estrofe, volta-se à "parte A", com sua mesma estrutura métrica e rímica. Mas agora as imagens ganham uma concretude sociocultural nova, que dá outra espessura histórica à canção. Na chuva de novembro da estrofe anterior, quem dança é Fred Astaire - "Je voudrais du Fred Astaire" [Eu queria Fred Astaire] - e o que se sonha é estar nos ares voando com Saint-Exupéry em seu avião - "Revoir un Latécoère" [Rever um Latécoère]. Estamos aqui diante de um dos referentes mais opacos, sobretudo para o jovem ouvinte que muito provavelmente não sabe que Latécoère era o avião do mundialmente conhecido autor de $O$ pequeno príncipe. Rever essa imagem é, de certo modo, uma vez mais, voltar no tempo e ir lá onde se encontra a amada a quem o príncipe fiel sempre serve - "Je voudrais toujours te plaire" [Queria sempre te agradar] - em seu imaginado jardim de inverno.

As paisagens idílicas se deslocam para outros campos na última estrofe. A primeira delas - "Je veux déjeuner par terre" [Eu quero um almoço sentado no chão] -, nos leva a uma espécie de piquenique no gramado de algum parque. Para um ouvinte francês, contudo, não é difícil supor que ele reconheça uma alusão ao famoso quadro de Manet "Déjeuner sur l'herbe" [almoço na relva], até pela proximidade sonora entre "terre" e "herbe". O verso seguinte tem também importante alusão, mas desta vez ao universo da canção: "Comme au long des golfes clairs", sem dúvida uma referência direta à canção de Charles Trenet "La mer" (la mer, qu'on voit danser au long des golfes clairs...)

Temos, desse modo, ao longo de toda a canção, por caminhos variados, uma justaposição de alusões, primeiramente as mais íntimas e familiares das rendas, chaleiras e fotografias, seguidas de uma alusão geográfica à Nova Inglaterra. $\mathrm{Na}$ "parte B", mergulhamos no espaço da memória, o que reforça o caráter nostálgico da canção. Caráter esse explorado a partir de um conjunto de referências ao universo do cinema de Fred Astaire, da literatura de Saint-Exupéry, da pintura de Manet e da canção francesa de Trénet. 
Os últimos versos da canção, talvez os menos felizes, “T'embrasser les yeux ouverts" [Te beijar de olhos abertos], nos permitam levantar uma importante questão. Quando estamos diante de uma canção, em que o verso final da estrofe se repete como um refrão determinando de modo estrutural a rima, muitas vezes, importa mais manter essa estrutura do que garantir a força de uma imagem isoladamente. É claro que as grandes canções são aquelas em que a relação entre rima e imagem são potentes e evocadoras, isso não impede que, mesmo em grandes canções, haja momentos em que essa relação seja menos bem resolvida. É certo que ao se recriar a canção, a centralidade de algum elemento formal, no caso aqui a rima, será determinante para o projeto. Antes de nos debruçarmos sobre esses aspectos formais, parece importante traçar, ainda que brevemente, um perfil da tradutora, uma vez que a perspectiva aqui adotada, na esteira do que é proposto por Low, considera necessariamente o contexto de recepção.

\section{Bïa Krieger em cena}

Como aponta Raissa Conde (2018) em entrevista recente feita com a tradutora, "radicada há mais de vinte anos na França e no Canadá, Bïa Krieger conquistou um público cativo nesses países, onde recebeu prêmios importantes, como o Grand Prix de l'Académie Charles Cros (França), Prix de l'Adisq (Canadá) e Félix du Meilleur Album Musiques du Monde (Canadá)". Esse lugar faz com que Bïa seja uma relevante mediadora cultural entre o Brasil e o universo francófono, tendo sido ela a responsável pelo maior número de canções brasileiras vertidas para o francês (BARROS, 2010, p.264). Essa carreira iniciou-se na França, em 1997, como a gravação de seu primeiro disco, Mémoire du vent, pela gravadora Saravah, de Pierre Barouh, considerado por muitos o embaixador da Bossa Nova na França. Ao lado de Barouh, ela traduziu e interpretou clássicos da MPB, entre os quais "Nuit de masques" [Noite dos mascarados] e "Samba Saravah" [Samba da Bênção]. É nesse contexto que surge o convite, em 2000, para verter para o português "Jardin d'hiver".

Tratava-se de projeto criado por Henri Salvador na esteira do sucesso mundial alcançado por sua volta à cena musical com Chambre avec vue. Salvador teve então a ideia de fazer um novo álbum com versos dessas 
canções em diferentes línguas, cabendo a Bïa Krieger cuidar da tradução para o português de "Jardim d'hiver". Como seria gravada pelo próprio Henri Salvador, a canção deveria se adequar de modo bastante estrito ao arranjo já existente e às inflexões da voz de Henri Salvador, o que exigiu de Bia um trabalho em grande medida informado pelos critérios descritos por Peter Low.

\section{Aqui neste jardim}

Como apontamos no início deste trabalho, traduzir canção é operar dentro de uma complexa equação em que estão em jogo tanto a dimensão musical quanto a dimensão textual. Para dar conta desse complexo, Peter Low elaborou o que chamou de "princípio do pentatlo" (penthatlon principle), isto é, cinco critérios que se bem articulados podem levar a uma tradução bem sucedida de canção.

Como vimos, "Jardim d'hiver" é uma canção em que as referências culturais são de grande importância, mas o que há de mais estruturante no texto e que garante toda sua arquitetura é a repetição, no final de quatro das cinco estrofes do verso "Dans mon jardin d'hiver" [em meu jardim de inverno]. Além de estar no título da canção, a rima final em [ER] é fundamental. Chegar a uma tradução satisfatória para esse verso foi seguramente ponto central no início do processo de criação. Não que este seja sempre o caminho, pois, como lembra Bia Krieger quando perguntada por Raissa Conde se costuma estabelecer hierarquia entre os aspectos semânticos, sonoros, elementos formais e estilísticos da letra:

\footnotetext{
O que eu não vou assinar embaixo é da palavra hierarquia. Vai ser sem hierarquia. Tudo isso vai ser importante, mas não existe uma ordem que sirva para todos esses elementos. Em cada música, eu vou ter, num cantinho da minha sensibilidade, do meu cérebro, da minha caneta, todos esses aspectos — semânticos, sonoros, elementos formais e estilísticos —; é sempre uma espiral que vai indo e que volta para o começo. E eu reviso tudo em função de algo que considerei um bom achado. Se aquele bom achado ficou acima da média de todos os meus outros achados, vou recomeçar tudo em função dele. Talvez essa seja a pedra angular. Ela não é óbvia. Costumo dizer a mim mesma: "acho que vou ter que recomeçar porque essa frase melhorou a qualidade da música. Então agora que eu recomecei, vou dar uma refinada na parte sonora. Agora que estou vendo que estou entrando bem na letra, vou procurar enriquecer um pouco as minhas rimas. Vou
} 


\begin{abstract}
procurar um vocabulário que tenha mais a ver com o vocabulário rico ou pobre." São como várias camadas de verniz, uma atrás da outra. A primeira é bem bruta, é bem assim: "há alguma frase aqui que, de cara, eu já sei como vou falar?" Então vou procurar alguma portinha de entrada. Se ela se abrir rápido, vai permitir que eu faça um primeiro rascunho, onde talvez haja frases que estão ali somente para ocupar espaço, e que vão desaparecer pouco a pouco. Na hora da revisão, é importante se perguntar: "essa não é uma linguagem preciosa demais para uma música que inicialmente era toda simples? Será que eu fui para um lado que não combina com a música?” Aí é feita também a revisão da parte musical, dos aspectos sonoros. (CONDE, 2018, p.195)
\end{abstract}

Como se pode notar, o processo de reescrita passa por um "achado" ou, se preferirmos, uma "pedra angular". Imagem da arquitetura, a pedra angular é o ponto de apoio de toda a construção. A pedra angular pode, pois, ser compreendia, como a palavra ou frase sem a qual parece desmoronar toda a construção poética da canção. Enquanto ela nos foge, o resto da letra custa a fazer sentido, empobrece, fica forçada. Ela é ao mesmo tempo o arcabouço e a síntese. No caso de "Jardin d'hiver", foi a decisão de traduzi-lo por "Jardim" que organizou todo o resto da canção, como se pode notar abaixo: 


\begin{tabular}{|l|l|}
\hline Jardin d'hiver & Jardim \\
Je voudrais du soleil vert & Eu só quero um sol verdim \\
Des dentelles et des théières & Pé de manga e de jasmim \\
Des photos de bord de mer & Muita fita do Bomfim \\
Dans mon jardin d'hiver & Aqui no meu jardim \\
Je voudrais de la lumière & Quero figa de marfim \\
Comme en Nouvelle Angleterre & Afastando o que é ruim \\
Je veux changer d'atmosphère & Respirar pirlimpimpim \\
Dans mon jardin d'hiver & Aqui no meu jardim \\
Ta robe à fleur & A chuva cai \\
Sous la pluie de novembre & Inundando o capim \\
Tes mains qui courent & Do mesmo céu \\
Je n'en peux plus de l'attendre & Você veio pra mim \\
Les années passent & O tempo vai \\
Qu'il est loin l'âge tendre & Quanto tempo já foi \\
Nul ne peut nous entendre & Ninguém mais só nós dois \\
Je voudrais du Fred Astaire & Quero ouvir o passarim \\
Revoir un Latécoère & Assobiando Tom Jobim \\
Je voudrais toujours te plaire & Cachoeira e mar sem fim \\
Dans mon jardin d'hiver & Aqui no meu jardim \\
Je veux déjeuner par terre & Quero um cheiro de alecrim \\
Comme au long des golfes clairs & Tua beleza Diadorim \\
Dans mosser les yeux ouverts & E te ouvir dizer que sim \\
Je veux déjeuner par terre & Aqui no meu jardim \\
Comme au long des golfes clairs & Quero um corte de cetim \\
T'embrasser les yeux ouverts & Samambaia no xaxim \\
Dans mon jardin d'hiver & E te ouvir dizer que sim \\
\hline
\end{tabular}

Ao compararmos o texto de partida com sua reescrita em português, nota-se imediatamente que o deslocamento do " jardim de inverno" 
para sua versão mais geral "jardim" trouxe consigo um deslocamento sociocultural importante, que poderíamos chamar de "aclimatação"1. Em certo sentido, essa escolha e as consequências que ela acarretou no desenvolvimento da canção em português articula todos os cinco critérios de Peter Low. Quando ouvimos "Aqui no meu jardim" temos a mesma distribuição acentual de "Dans mon jardin d'hiver". Como se trata de um verso-refrão repetido no final de cada estrofe, ele de fato assenta toda a canção, garantindo-lhe pela rima e pelo ritmo tanto naturalidade quanto cantabilidade. Temos assim já quatro dos critérios de Low contemplados, restando-nos comentar o quinto: "o sentido" (sense), critério este que, a nosso ver, toca num dos pontos fulcrais da tradução de canção que é, para retomar os termos de Even-Zohar, a "transferência intersistêmica".

Talvez mais do que na tradução de um poema, a reescrita da canção exija, para garantir sua comunicabilidade, um deslocamento sociocultural mais profundo do que no texto escrito. O que costuma interessar na canção é o acesso mais imediato à mensagem; mensagem aqui entendida como o complexo formado por letra e música. Se não houver adesão do ouvinte, a canção está fadada ao esquecimento. No caso de "Jardim", as transferências intersistêmicas visaram mergulhar o receptor num espaço referencial em que pudesse se reconhecer, num processo radical e vivo de naturalização.

Assim, já no primeiro verso da primeira estrofe temos “Eu só quero um sol verdim". Se por um lado guarda-se aqui a estranheza da imagem do um "sol verde" presente no texto de partida, por outro lado, a presença do diminutivo em "-im", tão característico do português falado, produz uma aproximação imediata do ouvinte, sobretudo se este conhecer Djavan e fizer ressoar o "sol amarelim" e o "amor azulzim" da canção "Azul". Nos versos seguintes, ao invés de nos remeter ao espaço interno da casa/jardim da canção em francês, com suas rendas, chaleiras e fotografias, somos convidados a passear por um quintal cheio de cheiros e sabores com suas mangas e jasmins. É outro jardim que é ativado, em certa medida, mais

\footnotetext{
${ }^{1}$ Esse termo foi usado por Glória Carneiro do Amaral para definir alguns projetos de reescrita de Baudelaire no Brasil. Cf. AMARAL, G. C. Aclimatando Baudelaire. São Paulo: Anna Blume, 1996.
} 
vibrante e colorido, certamente mais vivo. Essa nova paisagem que assim se anuncia define os contornos do caminho adotado a partir dessa pedra angular que, pela generalidade do "jardim" despido de qualquer inverno e pela especificidade da rima em -im, nos projeta para um clima bastante familiar a um brasileiro.

$\mathrm{Na}$ segunda estrofe, somos trazidos para o universo mágico afrobrasileiro por meio da "figa de marfim" que chega "afastando o que é ruim". Em seguida, surge uma lúdica referência literária com o "pó de pirlimpimpim" tão cara à Narizinho de Monteiro Lobato. Cruzam-se, assim, justapostos na estrofe, o mundo mágico dos terreiros de candomblé e o sítio encantado da infância com suas Cucas, Sabugos e Sacis.

Coerente com o projeto de tornar os referentes da canção mais vivos e vibrantes, o texto da "parte B" se distancia ele também do universo mais saudosista do texto de partida. Desse modo, a chuva que cai agora, ao invés de ativar memória de tempos idos, vem "Inundando o capim" e, ao invés de nos transportar para o passado, se quer presente - "Do mesmo céu/ Você veio pra mim". O que se produz assim é uma espécie de suspensão do tempo - “O tempo vai/ Quanto tempo já foi" - que presentifica “Ninguém mais/ Só nós dois"...

A contida alusão às "águas de março" da estrofe anterior, se explici-

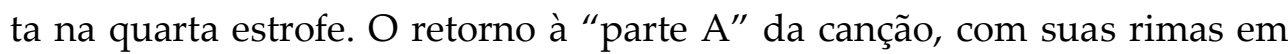
-im, se faz pela convocação do "passarim" que chega "assobiando Tom Jobim". Nesse gesto invertido, em que é o pássaro que assobia o cantor, reverbera a magia da estrofe anterior com seus "marfins/prilimpimpins". Estes agora vêm fluindo pelas múltiplas águas de uma "cachoeira" e de um "mar sem fim". Esse jogo de sons, cores e imagens desemboca, na estrofe seguinte, no "bom cheiro de alecrim". Se por um lado essa imagem amplia o espectro de cheiros anunciado no início - mangas, jasmins - por outro traz consigo outra importante referência à música popular brasileira. Desta vez é "Tanto mar" de Chico Buarque com seu "cheirinho de alecrim" que ressoa na canção... A imagem seguinte é outra importante referência à literatura: a "beleza Diadorim", com toda a ambiguidade que acarreta, evoca mais um dos grandes nomes da cultura brasileira, João Guimarães Rosa. 
Ao longo de todas essas estrofes, observa-se numa transferência invulgar de referentes culturais franceses, aclimatados aos trópicos; guardando contudo um provocador paralelismo, pois, assim como na canção em francês, são mobilizadas referências literárias e musicais. A maior diferença consistindo no fato de que as escolhas em português são mais solares e mais pulsantes. Diferentemente do texto de partida, o desejo explicitado na reescrita é o de querer ouvir o "tu" a quem o texto se endereça "dizer que sim"; mensagem reiterada no final da última estrofe. Nesta, ao invés da repetição que há em francês, surgem mais duas outras imagens "um corte de cetim" e "samambaia no xaxim", o que confirma o caráter mais profuso da versão brasileira.

\section{Provocações finais}

Para quem está acostumado com a ideia de tradução como a busca de uma fidelidade semântica, um projeto como este não será jamais tradução. Com efeito, é bastante comum chamar esse tipo de reescrita de versão. Para além das discussões terminológicas, o que nos interessa, sobretudo, é pensar na potência comunicativa e poética da canção na língua-cultura de chegada. Estamos aqui muito mais perto de Guilherme Gontijo Flores (2008) quando defende a ideia da tradução como diversão, do que exigir de uma reinvenção como a de "Jardim" qualquer resgate de uma imagem específica. Isso se deve à função que exerce um texto desse tipo no sistema sociocultural de chegada. No caso de "Jardim" sua eficácia pode ser medida pelo sucesso que alcançou, tendo sido, inclusive, regravada por Rosa Passos, entre outros...

Enfim, para além do sucesso na recepção, a comparação que fizemos acima deixa claro que há relevantes ressonâncias entre as duas canções. Em ambas, trata-se de um jardim imaginário onde lembranças são evocadas, cores e sons se correspondem, referências literárias e musicais são ativadas para criar uma atmosfera onde o desejo do encontro se faz, seja o encontro amoroso, seja o encontro entre música e poesia que só a canção sabe proporcionar. 


\section{Referências}

BARROS, Maria Lucia. La chanson francophone en classe de FLE au Brésil: un certain regard entre langues et cultures. Tese (Doutorado em Letras), Université Sorbonne Nouvelle-Paris 3, 2010.

CAMPOS, Augusto de. Balanço da bossa e outras bossas. São Paulo: Perspectiva, 1969.

CONDE, Raissa. Entrevista com a cantora e compositora Bïa Krieger. Tradterm 31, p.193-200, 2018.

FLORES, Guilherme Gontijo. A diversão tradutória: uma tradução das Elegias de Sexto Propércio - Belo Horizonte: UFMG / Faculdade de Letras / Programa Pós-Graduação em Estudos Literários, 2008. FLORES, Guilherme Gontijo \& GONÇALVES, Rodrigo Tadeu. Algo infiel: corpo performance tradução. Florianópolis: Cultura e Barbárie; São Paulo: n-1, 2017

LOW, Peter. Translating Poetic Songs - an attempt at a functional account of strategies. In: Target - International Journal of Translation Studies, v. 15, n¹, p. 91-110, 2003.

LOW, Peter. The Pentathlon Approach to Translating Songs. In: GORLÉE, Dinda L. (Ed.). Song and Significance - Voices and Virtues of Vocal Translation. New York: Rodopi, 2005.

TATIT, Luiz. Musicando a Semiótica - ensaios. São Paulo: Annablume, 1997.

\section{Discografia}

BÏA. Coeur vagabond. Audiogram, 2005.

PASSOS, Rosa. Rosa, Telarc Records, 2006.

SALVADOR, Henri. Chambre avec vue. Virgin Records, 2000. . Room with a view. Blue Note, 2002.

\section{Resumo}

O intuito deste trabalho é refletir sobre o modo como a canção "Jardin d'hiver", composta por Keren-Ann Zeidel, e Benjamin Biolay para ser interpretada, em 2000, por Henri Salvador em seu álbum Chambre avec vue, foi traduzida para o português por Bïa Krieger para ser gravada pelo próprio 
Henri Salvador em 2002 (https://www.deezer.com/en/track/3483754). Para embasar a análise parte-se, primeiramente, de uma breve descrição do contexto de produção da canção para, em seguida, por meio de discussão a respeito das implicações envolvidas no ato de se traduzir uma canção, pensar o que está em jogo nessa recriação.

Palavras-chave: Tradução de canção; “Jardin d'hiver"; Henri Salvador; Bïa Krieger.

\section{Résumé}

Le but de cet article est d'apporter une réflexion à la manière dont la chanson "Jardin d'hiver", (Keren-Ann Zeidel/Benjamin Biolay), écrite pour Henri Salvador et enregistrée dans son album Chambre avec vue (2000Virgin Records), a été traduite en portugais par Bïa Krieger à la demande d'Henri Salvador lui-même, qui l'a ensuite enregistrée en 2002 (https://www.deezer.com/en/track/3483754). Cette analyse repose, en premier lieu, sur une courte description du contexte de production de la chanson pour ensuite, au moyen d'une discussion autour des implications contenues dans l'acte de traduire une chanson, réfléchir à ce qui est en jeu dans cette re-création.

Mots-clés: Traduction de chanson; “Jardin d'hiver"; Henri Salvador; Bïa Krieger. 